\title{
Article
}

\section{Implementation in rehabilitation: a roadmap for practitioners and researchers}

Morris, Jacqui H., Bernhardsson, Susanne, Bird, Marie-Louise, Connell, Louise, Lynch, Elizabeth, Jarvis, Kathryn, Kayes, Nicola M., Miller, Kim, Mudge, Suzie and Fisher, Rebecca

Available at http://clok.uclan.ac.uk/28316/

Morris, Jacqui H., Bernhardsson, Susanne, Bird, Marie-Louise, Connell, Louise ORCID: 0000-0002-0629-2919, Lynch, Elizabeth, Jarvis, Kathryn ORCID: 00000001-5963-7346, Kayes, Nicola M., Miller, Kim, Mudge, Suzie et al (2020) Implementation in rehabilitation: a roadmap for practitioners and researchers. Disability and Rehabilitation, 42 (22). pp. 3265-3274. ISSN 0963-8288

It is advisable to refer to the publisher's version if you intend to cite from the work. http://dx.doi.org/10.1080/09638288.2019.1587013

For more information about UCLan's research in this area go to

http://www.uclan.ac.uk/researchgroups/ and search for < name of research Group>.

For information about Research generally at UCLan please go to http://www.uclan.ac.uk/research/

All outputs in CLoK are protected by Intellectual Property Rights law, including Copyright law. Copyright, IPR and Moral Rights for the works on this site are retained by the individual authors and/or other copyright owners. Terms and conditions for use of this material are defined in the policies page.

\section{CLoK}

Central Lancashire online Knowledge www.clok.uclan.ac.uk

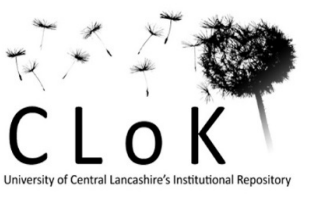




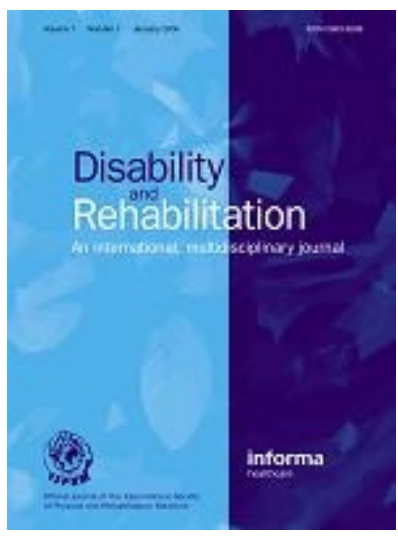

\section{Implementation in rehabilitation: A roadmap for practitioners and researchers}

\begin{tabular}{|r|l|}
\hline Journal: & Disability and Rehabilitation \\
\hline Manuscript ID & TIDS-11-2018-108.R1 \\
\hline Manuscript Type: & Perspectives in Rehabilitation \\
\hline Keywords: & $\begin{array}{l}\text { Knowledge Translation, Rehabilitation, Implementation science, } \\
\text { Implementation Context }\end{array}$ \\
\hline \multicolumn{2}{|l}{} \\
\hline
\end{tabular}

\section{SCHOLARONE ${ }^{\mathrm{M}}$ Manuscripts}




\section{Implications for Disability and Rehabilitation}

- Effective implementation of research evidence into rehabilitation practice has many interconnected steps and a roadmap analogy is helpful in defining them

- Understanding context for implementation is critically important and using theory can facilitate development of understanding

- Research methods for implementation in rehabilitation should be carefully selected and outcomes should evaluate implementation success as well as clinical change

- Sustainability requires regular revisiting of the interconnected steps 


\begin{abstract}
Purpose

Despite growth in rehabilitation research, implementing research findings into rehabilitation practice has been slow. This creates inequities for patients and is an ethical issue. However, methods to investigate and facilitate evidence implementation are being developed. This paper aims to make these methods relevant and accessible for rehabilitation researchers and practitioners.
\end{abstract}

\title{
Methods
}

Rehabilitation practice is varied and complex and occurs within multilevel healthcare systems. Using a "road map" analogy, we describe how implementation concepts and theories can inform implementation strategies in rehabilitation. The roadmap involves a staged journey that considers: the nature of evidence; context for implementation; navigation tools for implementation; strategies to facilitate implementation; evaluation of implementation outcomes; and sustainability of implementation. We have developed a model to illustrate the journey, and four case studies exemplify implementation stages in rehabilitation settings.

\section{Results and Conclusions}

Effective implementation strategies for the complex world of rehabilitation are urgently required. The journey we describe unpacks that complexity to provide a template for effective implementation, to facilitate translation of the growing evidence base in rehabilitation into improved patient outcomes. It emphasises the importance of understanding context and 
application of relevant theory, and highlights areas which should be targeted in new implementation research in rehabilitation.

KEY WORDS: Knowledge Translation, Rehabilitation, Implementation Science, Implementation Context 


\section{Introduction}

Rehabilitation science is a rapidly growing field, leading to an explosion in research to inform rehabilitation practice [1]. Just in the past four years, the number of published randomized controlled trials in rehabilitation (RCTs) have increased by approximately 2,200 per year [1]. Rigorous trials of rehabilitation interventions, some of which have been conducted internationally [2], innovative evidence synthesis [3], and thousands of evidence based guidelines are all contributing high quality evidence to inform rehabilitation practice [1].

Despite these developments, translating research findings into rehabilitation practice is slow. Use of research evidence among rehabilitation practitioners varies considerably [4-12] and evidencebased practice guidelines often are not fully implemented [13-15]. Typically patients receive a mix of evidence-based and non-evidence-based interventions $[9,16,17]$, indicating that research does not automatically influence practice $[18,19]$. However, where evidence-informed rehabilitation recommendations have been systematically implemented, benefits for practitioners and patients occur. [20]

Failure to translate research into practice creates ethical issues. Moral and actual harm occurs when strategies known to improve peoples' lives are received only by a few, or when ineffective interventions continue to be delivered [19].

However, translating research knowledge into rehabilitation practice is not straightforward, and publication of research evidence is only one step in the process. Rehabilitation is a complex multidisciplinary process with many moving parts. It is conducted within complex multi-level healthcare 
systems, involving interactions between healthcare professionals, teams and managers, patients, families and carers. Organisational context and culture, clinical and professional context and team working and leadership all determine if and how research knowledge is implemented [21] Transitions from acute and inpatient rehabilitation settings to outpatient primary care and community rehabilitation settings make translating knowledge into rehabilitation practice even more complex. Understanding these factors and their interactions will inform strategy development and testing to facilitate knowledge translation for practice, increasing the likelihood for rehabilitation research efforts to make a meaningful difference to rehabilitation practice and outcomes.

Implementation science is a rapidly evolving field concerned with learning how to translate and embed research evidence into practice to improve health outcomes [21-24]. Although the field of implementation research has grown in the last decade, the emergence of implementation research in rehabilitation is relatively recent. Although many guides to implementation science exist, the evolving nature of rehabilitation research means an introduction for rehabilitation researchers and clinicians interested in implementation science, and its potential impact for rehabilitation practice, is timely. This is particularly so, given the complex and highly specific context of rehabilitation, which requires unique strategies for translating research knowledge into practice.

\section{Methods}

Using the analogy of a journey towards effective implementation, we have developed a "Roadmap" for implementation research in rehabilitation. This is not an exhaustive review, but by sharing lessons learned from our international group, we intend to offer insight, and create momentum for implementation research in rehabilitation. The roadmap and its stages are described in Figure 1. It 
illustrates considerations for each stage of the journey, and shows how these must be revisited to ensure stustainability of implementation over time through a central circle denoting how sustainability can be facilitated.

We developed the roadmap from four case studies describing research conducted in international rehabilitation settings by some of the authors of this paper to provide examples of key implementation concepts, theories and methods, and to demonstrate their application in a rehabilitation research context (Table 1). The roadmap was developed by examining the strategies used in these studies, and by exploration of the processes researchers adopted for implementation within the case studies. At the roadmap destination, travellers will have a broad sense of the current landscape in terms of what is currently known about factors which may help or hinder implementation efforts and related strategies, as they apply in a rehabilitation context. We hope this will provide a solid platform on which to further advance knowledge and practice for more timely and efficient knowledge translation in rehabilitation.

Insert table 1 about here.

Insert Figure 1 about here

\section{The Roadmap}

\section{A: The journey begins. What do we mean by evidence?}

As rehabilitation researchers, our primary focus is on evidence derived from research. However, evidence takes multiple forms. Local data, clinical reasoning, evaluation, and even tacit knowledge 
[25], patient experience, and organisational information all provide evidence to inform implementation efforts. Reconciling tension between clinical trial evidence cited in clinical guidelines, derived from the average patient within a highly standardised sample, against what is best for individual patients presenting in rehabilitation, is critical. Slavish devotion to evidence based guidelines irrespective of factors relevant to the individual, is amoral, placing patients at risk of inappropriate treatment [26]. Thus, Bowen and Graham [27] (page S4) suggest evidence-informed (rather than evidence-based) practice because "(1) research to inform complex problems facing health systems is often incomplete, (2) much research is contradictory, and (3) non-research forms of evidence can be legitimately used in decision-making". These arguments reflect our pragmatic approach to real-world rehabilitation research, and we fully support the use of multiple forms of evidence drawn from different sources.

\section{Roadmap B: Planning the route to avoid roadblocks: The importance of context}

Why do some therapists adopt evidence-informed interventions, when others do not $[15,17,28]$ and why is it that improvement initiatives work in some settings but not in others? $[29,30]$. In implementation research, the term context has been used to describe factors that influence intervention adoption, effectiveness or sustainability in real world settings. Appreciation and planned investigation of context aids identification of possible routes to take in this type of research and enhances clarity about potential obstacles on the journey [31].

Investigating context facilitates understanding of "what happens when a particular intervention is joined together with an individual, team, organisation or healthcare system" [32] (page 109). Considering context at each of these levels is important for informing targeted strategy development. For example, investigating effects of strategies designed to influence therapy practice 
requires exploration of therapist knowledge, behaviour, and actual treatment of patients (i.e. informing strategies targeted at the individual level) [15] [28]. Conversely, investigating adoption of evidence-based services, such as hospital-based stroke rehabilitation or early supported discharge (ESD), requires investigation of team working and organisational influences (i.e. strategies targeted at the team and organisational level) $[33,34]$.

Context is dynamic and changes over time, therefore it should be considered as a process. Often context is reduced to environment or place of intervention delivery, to identify discrete contextual factors [35]. However context can also include individual factors and human agency, making understanding staff and patient perspectives crucial. As Bate points out "how we think about context will determine how we go about researching and ultimately trying to manage it" [36] (page 20).

In rehabilitation, implementation research is particularly challenging, because intervention and context overlap. For example in group therapy, it may not be clear which intervention components are essential for the therapeutic effect, and which can be deemed context. Yet, this is critical, because adaptations are often necessary in order for interventions to be adopted, or sustained over time. Damschroder's emphasis on identifying core intervention components (active ingredients) and clear hypotheses about intervention mechanisms of action are crucial [21]. If the active ingredients of an intervention are known, other aspects of the intervention can be adapted to facilitate adoption without fundamentally changing the intervention. This approach should maintain the effectiveness of the intervention [37]. 
Implementation research requires a shift in thinking from the gold standard randomised controlled trial model $[36,38,39]$. This design was developed for testing drugs, and requires identical interventions to be delivered across sites under controlled circumstances to ensure any observed effect can be attributed to the drug. However, in a complex rehabilitation intervention, intervention effect cannot be removed from the context in which it is delivered and indeed, observed effect may arise through a combination of intervention content, delivery and context. As such, investigations into how interventions should be adapted for complex rehabilitation delivery contexts whilst maintaining their active ingredients are necessary, but lacking. [37]. Such investigation is crucial to optimise the likelihood for rehabilitation interventions to be adopted and sustained in real world settings, and is why implementation research is so important.

\section{Roadmap C: What tools can help us navigate? Implementation theory}

Important tools for implementation research are theories, models and frameworks developed to understand implementation success and failure, and to guide and evaluate implementation efforts [40]. Theories exist to facilitate generalisation, replicability and effectiveness of implementation strategies [41]. Using theory in implementation research is recommended by many and its use has increased considerably in recent years [42] [43]. However, a scoping review published in 2010, examining use of three theories in implementation research in rehabilitation, medicine and nursing, [44] demonstrated infrequent use of these theories to inform implementation research in rehabilitation, compared to studies within medicine and nursing. The review suggests the use of theory in rehabilitation is in its infancy, compared to its more prevalent use in other fields of health research. 
Selecting appropriate theoretical approaches is challenging as there are more than 100 relevant theories [45]. To aid theory selection, theories can be categorised according to three general aims, as proposed by Nilsen [40]:

1) Determinant frameworks, classic or implementation theories: to optimise understanding and/or explain what influences implementation outcomes

2) Process models: to describe or guide the translation of research into practice

3) Evaluation frameworks: to evaluate implementation.

Here we exemplify how these aims influenced selection of theoretical approaches in our case study examples (see Table 1).

\section{Theories used to facilitate understanding of factors influencing implementation:}

The Consolidated Framework for Implementation Research (CFIR) integrates multiple existing implementation theories. It provides a comprehensive framework for understanding multifactorial influences on implementation [21]. These influences span intervention characteristics, individuals and teams involved in implementation and their interactions, internal organisational characteristics, and wider external drivers for change. In Case study 1, Fisher and colleagues used CFIR to analyse and identify core components of an Early Supported Discharge intervention, and to understand how components should be adapted to real-world contextual factors. In Case study 2, Connell and colleagues used CFIR to explore how an upper limb rehabilitation intervention for stroke rehabilitation was implemented in practice. It was also used for survey design to elicit characteristics of rehabilitation therapists and settings where implementation occurred. In both case studies, the CFIR guided identification of how networks, team communication, leadership and preconceptions of the intervention influenced implementation, facilitating strategy development for improving implementation. 
Normalisation Process Theory (NPT) is a conceptual framework for understanding how new technologies and complex interventions are operationalized in everyday work [35]. It examines how people make sense of the intervention, how they commit to implementing it, how they work together to make implementation happen, and how they individually and collectively appraise implementation. In Case study 4, Mudge and Kayes used NPT to analyse data from patients and staff participating in a pilot trial. Experiences of implementation in practice were explored and findings informed revisions to the Toolkit intervention as well as the planned implementation processes. In Case Study 2, NPT was used to explore processes involved in identifying, integrating and embedding an evidence-based upper limb training program for stroke in practice. Although useful in identifying individual and collective experiences, it did not capture wider contextual factors that influenced implementation, confirming that one theory in isolation is often insufficient for identification of the diverse influences on implementation.

\section{Theories used to guide the process of translating research into practice:}

The Grol and Wensing Implementation model [46] is a process model, developed to support and guide implementation. It was used to guide development of a tailored implementation strategy for clinical practice guidelines in primary care physiotherapy (Case study 3 ). The model was selected because it integrates theories from several research fields, including behavioural change theories, and provides a structured, pragmatic, approach for implementation. It proved to be a comprehensive tool for addressing factors requiring consideration in a rehabilitation implementation project.

The Behaviour Change Wheel (BCW) [47] was developed by systematic synthesis of behaviour change frameworks to support behaviour change intervention development. It seeks to identify 
and understand aspects of capability, opportunity and motivation that need to be addressed to facilitate the desired behaviours, and to match them to relevant behaviour change techniques. Whilst the BCW focuses on changing an individual's behaviour, it also includes policy categories to address system-level influences. In Case study 2, the BCW was used to guide development of a behaviour change strategy to enable therapists to implement strategies to increase intensity of upper limb exercise in stroke rehabilitation. In this context, the taxonomy of behaviour change techniques was useful to inform implementation strategies development.

\section{Theories used to guide evaluation of implementation}

Evaluation of implementation is often an iterative process, with findings facilitating tailoring of implementation strategies, for subsequent re-evaluation. In Case study 4, NPT informed our analysis of a pilot study of implementing the Living Well Toolkit in practice in four rehabilitation settings. We were able to respond to the findings by making some changes to the implementation of the toolkit, including the development of introductory videos to simplify the explanation of the toolkit, development of an additional version of the toolkit and development of a tiered training package. The first tier of training involved everyone (including administrators) to ensure a shared philosophy for the toolkit. Stakeholders were trained to embed systems and to reflect on practice, organising opportunities to share reflections of successes, challenges and tensions in embedding the toolkit into practice. This in turn facilitated development of strategies for managing the implementation process [48].

From our case studies examples, it is clear that targeted selection of frameworks for specific implementation purpose is critical. One framework or theory is unlikely to address all facets of 
implementation and selection of the appropriate framework that is fit for purpose requires careful consideration.

\section{Roadmap D: Making sure the journey happens: Implementation strategies}

Despite the theories and frameworks available to guide implementation processes, a 2015 review [49] highlights that implementation strategies in rehabilitation have relied on educational strategies as the primary intervention tool. This is despite some evidence suggesting active, multi-component implementation strategies might be more effective $[20,50,51]$. Educational strategies alone may improve clinician knowledge and skill, however they do not necessarily result in implementation, particularly when didactic and passive strategies are used $[52,53]$ are examples, but there are others. Other implementation strategies that have been shown useful in rehabilitation settings include multifaceted training packages, journal clubs, and contextualised guidelines [54].

As we have alluded to above, differentiating mandatory 'active ingredients' and effective elements of desired practice, from those that are optional and can be adapted, helps to address tensions between the need for local contextualisation and fidelity $[28,55]$. Furthermore, tools and strategies informed by theories discussed above, are necessary for uptake and sustained implementation. A plethora of different implementation strategies have been described and used, and, as with theories, choosing the appropriate ones can be challenging. A recent overview of implementation strategies by Leeman et al [56] provides a useful classification of strategies and suggested terminology. The purpose was to increase consistency in reporting and facilitate comparisons and synthesis of findings, as well as aligning strategies with relevant theories, and finding strategies that best match specific needs [56]. 
In considering what tools are appropriate and when, we define three stages of the implementation process (planning, implementation and monitoring), provide examples of tools to support each stage, and associated considerations for research and practice. These are presented in Table 2. A number of the tools referred to in Table 2 are derived from the theories and frameworks described above. For example, CFIR offers a practical framework for exploring in-depth the factors which may help or hinder uptake within a specific context during the planning stage. Similarly, the NOMAD tool was developed drawing on NPT to use with staff involved in implementation activities and can inform the development of more targeted implementation strategies. As well as drawing on tools derived from relevant implementation theories, Table 2 also provides examples of a range of other strategies discussed in the literature which have been argued to support the implementation process, such as structural supports, communities of practice, knowledge brokerage; and review and monitoring processes which may contribute to more sustained change (discussed in more detail below). The practical considerations presented alongside each stage are not exhaustive, but rather are some of the authors' collective learning from the case studies in Table 1.

\footnotetext{
Roadmap E: How do we know we have followed the right road? Implementation Research Designs The complexity of rehabilitation interventions coupled with the multi-factorial systems-orientated nature of implementation means multiple methodological approaches and research designs are required to investigate implementation. Peters et al. (2013) summarise implementation research objectives, which, together with our case studies, we use to illustrate some implementation research designs [57].
} 


\section{Explore}

Here, the objective is to explore a phenomenon, develop understanding and make generalisations for subsequent testing. Case study 1 aimed to explore implementation contexts for ESD services after stroke, and to identify factors that facilitate or impede implementation. The purpose was to identify adaptable elements of context that could be modified to enable embedding of ESD in practice. The design was an exploratory qualitative design using interviews with key stakeholders. The novel exploratory work informed a subsequent implementation study [58]. In Case study 3, determinants of guideline use by musculoskeletal physiotherapists were investigated in a survey, as a first step in a model-supported implementation project, and the implementation strategy was tailored to address the identified determinants.

\section{Describe}

A starting point in implementation research is often description of a phenomenon or context, with identification of correlates and possible causes as another potential objective. Within Case study 2, a qualitative study and a survey, informed by CFIR, together described rehabilitation contexts. Contextual information informed development of specific behaviour change strategies to support implementation of increased dose of upper limb rehabilitation [28].

\section{Influence}

Influencing change in specific outcomes is of course the overall aim of implementation research. Research designs for evaluating implementation strategies fall along a continuum between uncertainty and certainty of effectiveness. Design selection is informed by the desired degree of probability that effects are due to the intervention [57] . In most implementation research, the rehabilitation interventions being implemented are likely to have proven efficacy (demonstrated 
through an RCT conducted in ideal circumstances). What is of most interest is the effectiveness of the rehabilitation intervention in practice (effect in a real world setting). The real-world nature of implementation research therefore challenges researchers to see beyond the RCT design [39]. It thus may be appropriate to utilise uncontrolled before and after studies (Case study 1 ) or time series designs to examine whether implementation is occurring over time.

In participatory action research, researchers and participants work together to collect data, take action where this is supported and reflect on the process [59]. It is another rigorous method by which change can be iteratively implemented and evaluated in a given context, and that tolerates uncertainty, but is not expected to generalise beyond that setting.

Realist methodologies may also be useful to gain an understanding of what works, for whom and in what circumstances [60]. Using this approach in implementation research could lead to more targeted implementation activities which build on an understanding of how the intervention operates in specific contexts and then leads to specific outcomes [29].

Design selection should therefore stem from evaluation of both implementation aims, tolerance of uncertainty and an appreciation of context.

\section{Roadmap F: How do we know if we've got to the destination? Implementation outcomes}

The primary outcomes within rehabilitation are clinical and patient-recorded outcomes, which are relevant when examining how well rehabilitation interventions operate in real world settings [58]. However, clinical outcomes are distal when establishing effects of implementation or facilitation strategies, as they depend on successful implementation. To understand, develop and evaluate how 
well implementation strategies are working it is salient to examine conceptually distinct implementation outcomes. Proctor et al. define specific implementation outcomes, which include acceptability, adoption, appropriateness, costs, feasibility, fidelity, penetration and sustainability of the implementation strategy [61]. These are implementation outcomes thought necessary to mediate and sustain change in clinical outcomes [62]. Implementation outcomes can be examined using quantitative or qualitative methods.

In both Case study 2 and 3, implementation outcomes were examined. In Case study 2, the effects of an implementation strategy aiming to change therapists' behaviour in delivery of dose of upper limb rehabilitation after stroke were measured. Therapists' behaviours, as well as their perceptions of acceptability, appropriateness and compatibility with practice, were examined using qualitative methods informed by NPT. Feasibility, or practicability of implementation within the context of the study sites was indicated through audit, which recorded performance of the desired staff behaviours, and discrepancies between sites were examined through evaluation within the interviews. Accounts of difficulties experienced in maintaining momentum for implementation in a planned way were also elicited in Case study 2 by capturing implementation rather than clinical outcomes. In this way, knowledge to inform future adaptation of the implementation strategy and processes was generated. This comprehensive case study illustrates how critical implementation outcomes can be examined, and how they reflect the success, or not, of implementation efforts in different settings. The study identified differences in implementation success across sites, developing generalizable understanding about how implementation success can ultimately influence clinical outcomes. 
In Case study 3, implementation outcomes were also examined. Effects of the multi-component implementation strategy to increase use of clinical practice guidelines were measured in terms of therapists' attitudes (acceptability), access (feasibility) and behaviours, particularly those related to guideline use (adoption). Sustainability of the implementation is currently being measured in a longterm follow-up study.

\section{Roadmap G: How do we remain roadworthy over time? Sustaining implementation}

The behavioural and evolving nature of rehabilitation science and practice means sustainability requires action to preserve fidelity and intended effects of the implemented intervention. However, as CFIR suggests, sustainability is challenging, requiring continuous adaptation of the implemented intervention and the implementation strategy (Table 2). Clearly planning and systems for sustainability should be adopted. Identifying, anticipating and responding to factors that influence long-term sustainability should be considered as integral to implementation strategies [62].

Explicitly adopting a cyclical approach to review of implementation should ensure new evidence is implemented whilst accounting for internally and externally generated system changes $[62,63]$. Research evidence, once established as usual care, can become outdated. Considering how monitoring and review for sustainability can be conducted at the individual and organisational levels is critical. Tools such as the NOMAD mentioned above and models such as the Plan, Do, Study Act model (PDSA) [64] (page 135) within quality improvement can structure the process of sustainability. These methods are highly applicable and accepted in rehabilitation conducted within health service settings, and can facilitate continuous review and updating of rehabilitation practice, given its rapidly expanding knowledge base [65]. At any point in the sustainability cycle, return to other stages on the roadmap is possible, as highlighted in Figure 1. Building capacity for adaptation 
as the evidence base expands is also vital and requires continued learning and problem solving, and continuous evaluation of fit between the rehabilitation intervention and multi-layered context within the system [66].

\section{Conclusions and implications}

This paper provides a snapshot of the large and growing landscape of implementation research and was not intended as a comprehensive overview. Instead, our intention was to provide an introduction and guidance to implementation science for rehabilitation researchers and practitioners. In it we share empirical experiences of implementation research in rehabilitation contexts and map them to theoretical perspectives derived from the current implementation literature.

We have highlighted the importance of understanding the context in which implementation is to occur, and how implementation strategies should emerge from that understanding. We recognise, however, that future research needs to investigate more fully how specific contexts in rehabilitation influence implementation. We acknowledge too that engaging practitioners to understand what their knowledge needs are, will support better implementation in future. Developing creative ways to generate and provide knowledge to support implementation should be a focus for future research.

We have highlighted just a few of the many theoretical approaches and strategies that can be used to guide knowledge generation about context and to guide implementation. Our arguments are based on our own experiences, but we want to emphasize the importance to other researchers of choosing one or several of those theories and strategies so knowledge gained by research can be 
generalised and theories developed to match rehabilitation concepts. There is an urgent need for more theory-informed research to generate comparable and generalizable knowledge that will contribute to expanding the modest evidence base for successful implementation in rehabilitation. Research on implementation strategies which accounts for the unique and specific complexities of the rehabilitation context, will allow for a better understanding of what works, and what does not work, ultimately increasing our likelihood to meaningfully impact rehabilitation practice and outcomes.

We used a roadmap analogy to make the stages of conducting implementation research in rehabilitation explicit. These stages were exemplified by mapping of implementation components to the different parts of the road journey through rehabilitation studies conducted by some of the study authors. It is our hope that this roadmap, and the sharing of our own implementation research experiences, can lead to more rehabilitation researchers embarking on this important journey. We hope it will support their endeavours in exploring, implementing, and sustaining evidence-informed practices within their context. 


\section{References}

1. Kamper SJ, Moseley AM, Herbert RD, et al 15 years of tracking physiotherapy evidence on PEDro, where are we now? Br J Sports Med 2015; 49: 907-909.

2. AVERT Trial Collaboration Group. Efficacy and safety of very early mobilisation within 24 hours of stroke onset (AVERT): a randomised controlled trial. Lancet. 2015; 386: 46-55.

3. Pollock A,Farmer SE, Brady MC et al. Interventions for Improving Upper Limb Function After Stroke. Cochrane Database Syst Rev. 2014; 11: CD010820. doi: 10.1002/14651858.CD010820.pub2.

4. Jette DU, Bacon K, Batty C. Evidence-based practice: beliefs, attitudes, knowledge, and behaviors of physical therapists. Phys Ther. 2003; 83: 786-805.

5. Iles R, Davidson M. Evidence based practice: a survey of physiotherapists' current practice. Phys Res Int. 2006; 11: 93-103.

6. Hodder RK, Wolfenden L, Kamper SJ. Developing implementation science to improve the translation of research to address low back pain: A critical review. Best Pract Res Clin Rheumatol. 2017; 30: 1050-1073.

7. Holden MA, Nicholls EE, Hay EM et al. Physical therapists' use of therapeutic exercise for patients with clinical knee osteoarthritis in the United Kingdom: in line with current recommendations? Phys Ther. 2008: 88; 1109-1121.

8. Salbach NM, Guilcher SJT, Jaglal SB. Determinants of research use in clinical decision making among physical therapists providing services post-stroke: a cross-sectional study. Implement Sci. 2010; doi: $10.1186 / 1748-5908-5-77$

9. Liddle, S.D., Physiotherapists' use of advice and exercise for the management of chronic low back pain: A national survey. Man Ther. 2009; 14: 189-196. 
10. Hodder, R.K., et al., Developing implementation science to improve the translation of research to address low back pain: A critical review. Best Pract Res Clin Rheumatol. 2016; 30: 1050-1073.

11. Bernhardsson, S., et al., Determinants of guideline use in primary care physical therapy: a cross-sectional survey of attitudes, knowledge, and behavior. Phys Ther. 2014; 94: 343-354

12. Lindström $\mathrm{AC}$ and B. S., Evidence-based practice in primary care occupational therapy: a survey in Western Sweden. Occup Ther Int. 2018; doi.org/10.1155/2018/5376764

13. Royal College of Physicians. National sentinel stroke audit 2010. Clinical Effectiveness and Evaluation Unit Royal College of Physicians, London

14. Bernhardsson $\mathrm{S}$, Larsson ME, Eggertsen $\mathrm{R}$, Olsén MF, Johansson $\mathrm{K}$, Nilsen $\mathrm{P}$, et al. Evaluation of a tailored, multi-component intervention for implementation of evidencebased clinical practice guidelines in primary care physical therapy: a non-randomized controlled trial. BMC Health Serv Res. 2014; 14: 105.

15. Korner-Bitensky NJ, Desrosiers J, Rochette A. A national survey of occupational therapists' practices related to participation post-stroke. J Rehabil Med. 2008; 40: 291-297.

16. Mikhail C. Physical Therapists' Use of Interventions With High Evidence of Effectiveness in the Management of a Hypothetical Typical Patient With Acute Low Back Pain. Phys Ther. $2005 ; 85: 11$.

17. Bernhardsson S, Öberg B, Johansson K, Nilsen P, Larsson ME. Clinical practice in line with evidence? A survey among primary care physiotherapists in western Sweden. J Eval Clin Pract. 2015; 21: 1169-1177.

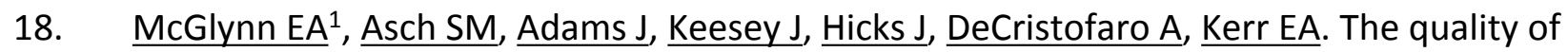
health care delivered to adults in the United States. New Engl J Med. 2003; 348: 2635- 
2645.

19. Solomon, MZ. The ethical urgency of advancing implementation science. Am J Bioethics. 2010; 10: 31-32.

20. Salbach NM, Wood-Dauphinee S, Desrosiers J, Eng JJ, Graham ID, Jaglal SB et al. Facilitated interprofessional implementation of a physical rehabilitation guideline for stroke in inpatient settings: process evaluation of a cluster randomized trial. Implement Sci. 2017: doi: 10.1186/s13012-017-0631-7

21. Damschroder LJ, Aaron DC, Keith RE, Kirsh S, Alexander JA, Lowery JC. Fostering implementation of health services research findings into practice: a consolidated framework for advancing implementation science. Implement Sci. 2009; doi.org/10.1186/1748-5908-4-50

22. Madon T, Hofman KJ, Kupfer L, Glass RI. Public Health. Implementation Science. Science. 2007; 318: 1728-1729.

23. Eccles MP, Mittman BS. Welcome to Implementation Science. 2006. Implementation Science; doi.org/10.1186/1748-5908-1-1

24. Lang ES, Wyer PC, Haynes RB. Knowledge Translation: Closing the Evidence-to-Practice Gap. Ann Emerg Med. 2007; 49: 355-363.

25. Dijkers, MP, SL Murphy, J Krellman. Evidence-based practice for rehabilitation professionals: concepts and controversies. Arch Phys Med Rehab. 2012; 93: S164-S176.

26. Greenhalgh T. Of lamp posts, keys, and fabled drunkards: A perspectival tale of 4 guidelines. J Eval Clin Pract. 2018; 24:1132-1138. 
27. Bowen SJ and ID Graham. From knowledge translation to engaged scholarship: promoting research relevance and utilization. Arch Phys Med Rehab. 2013; 94: S3-S8.

28. Connell, L.A, McMahon NE, Watkins CL, Eng JJ. Therapists' use of the Graded Repetitive Arm Supplementary Program (GRASP) intervention: a practice implementation survey study. Phys Ther. 2014: 94: 632-643.

29. Cadilhac DA, Andrew NE, Stroil Salama E On behalf of the Australian Stroke Clinical Registry Consortium, et al Improving discharge care: the potential of a new organisational intervention to improve discharge after hospitalisation for acute stroke, a controlled before-after pilot study BMJ Open 2017; 7: e016010. doi: 10.1136/bmjopen2017-016010

30. Power M, Tyrell P, Rudd AG, Tully M, Dalton D, Marshall M et al. Did a quality improvement collaborative make stroke care better? A cluster randomized trial. Implementation science. 2014; 9: 40. doi.org/10.1186/1748-5908-9-40

31. Papoutsi C, Boden R, Foy R, Grimshaw J, Rycroft-Malone J. Challenges for implementation science. In Raine R, Fitzpatrick R, Barratt H, Bevan G, Black N, Boaden, $R$ et al. Challenges, solutions and future directions in the evaluation of service innovations in health care and public health. Health Services and Delivery Research 2016; 16: 1-139. DOI: 10.3310/hsdr04160-105

32. Howarth E, Denvers K, Moore G, O'Cathain A, Dixon-Woods M. Contextual issues and qualitative research. In Raine R, Fitzpatrick R, Barratt H, Bevan G, Black N, Boaden, $\mathrm{R}$ et al. Challenges, solutions and future directions in the evaluation of service innovations in health care and public health. Health Services and Delivery Research 2016. 16; 4: 1-139. DOI: 10.3310/hsdr04160-105

33. Bayley MT, Hurdowar A, Richards CL, Korner-Bitensky N, Wood-Dauphinee S, Eng JJ. 
Barriers to implementation of stroke rehabilitation evidence: findings from a multi-site pilot project. Disabil Rehab. 2012; 34: 1633-1638.

34. Chouliara, N, Fisher RJ, Kerr M, Walker MF. Implementing evidence-based stroke Early Supported Discharge services: a qualitative study of challenges, facilitators and impact. Clin Rehab. 2014; 28: 370-377.

35. May CR, Mair F, Finch T, MacFarlane A, Dowrick C, Treweek S, Rapley T. Development of a theory of implementation and integration: Normalization Process Theory. Implement Sci. 2009; 4: 29. doi: 10.1186/1748-5908-4-29.

36. Bate P, Robert G, Fulop N, Ovretveit J, Dixon-Woods M. Perspectives on Context: A Collection of Essays Considering the Role of Context in Successful Quality Improvement. 2014. The Health Foundation. London.

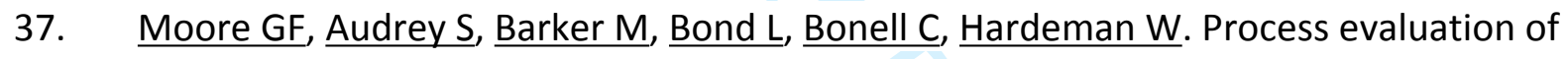
complex interventions. Complex interventions in health: an overview of research methods. 2015; 350: 1258. doi.org/10.1136/bmj.h1258

38. May CR, Johnson M, Finch T. Implementation, context and complexity. Implement Sci. 2016; 11: 141. doi.org/10.1186/s13012-016-0506-3

39. Kersten, P, Ellis-Hill C, McPherson KM, Harrington R. Beyond the RCT-understanding the relationship between interventions, individuals and outcome-the example of neurological rehabilitation. Disabil Rehab. 2010; 32: 1028-1034.

40. Nilsen P. Making sense of implementation theories, models and frameworks. Implement Sci. 2015; 10: 53. doi.org/10.1186/s13012-015-0242-0 
41. Rycroft-Malone J, Bucknall T (Eds.). Evidence based nursing series, Volume 2. Models and frameworks for implementing evidence-based practice: linking evidence to action. Singapore, John Wiley \& Sons; 2011.

42. Hudon A, Gervais MJ, and Hunt M. The contribution of conceptual frameworks to knowledge translation interventions in physical therapy. Phys Ther. 2015; 95: 630-639.

43. Liang L, Bernhardsson S, Vernooij RW, Armstrong MJ, Bussières A, Brouwers MC, Gagliardi AR. Members of the Guidelines International Network Implementation Working Group. Use of theory to plan or evaluate guideline implementation among physicians: a scoping review. Implement Sci. 2017:12:26. doi: 10.1186/s13012-0170557-0

44. Colquhoun, H.L Letts $\amalg$, Law MC, MacDermid JC, Missiuna CA.A scoping review of the use of theory in studies of knowledge translation. Can J Occup Ther. 2010; 77: 270-279.

45. Birken SA, Powell BJ, Shea CM, Haines ER, Kirk AM, Leeman J, et al. Criteria for selecting implementation science theories and frameworks: results from an international survey. Implement Sci. 2017; 12: 124. doi.org/10.1186/s13012-017-0656-y.

46. Grol R, Wensing M, Eccles M, Davis D (Eds.). Improving patient care: the implementation of change in health care, Second Edition. John Wiley \& Sons, Oxford, 2013:

47. Michie S, Richardson M, Johnston M, Abraham C, Francis J, Hardeman W, Eccles MP, Cane J, Wood CE. The behavior change technique taxonomy (v1) of 93 hierarchically clustered techniques: building an international consensus for the reporting of behavior change interventions. Ann Behav Med. 2013; 46: 81-95.

48. Mudge S, Sezier A, Payne D, Kersten P, Kayes N. Developing and putting into practice a Living Well Toolkit: a pilot study drawing on Normalisation Process Theory. Presented at 
New Zealand Rehabilitation Association Conference 2017: Christchurch, New Zealand.

49. Jones CA Roop SC, Pohar SL, Albrecht L, Scott SD. Translating knowledge in rehabilitation: systematic review. Phys Ther. 2015; 95: 663-677.

50. Bekkering, G., Hendriks HJ, van Tulder MW, Knol DL, Hoeijenbos M, Oostendorp RA, Bouter LM. Effect on the process of care of an active strategy to implement clinical guidelines on physiotherapy for low back pain: a cluster randomised controlled trial. BMJ Qual Safe. 2005; 14: 107-112.

51. Menon, A Korner-Bitensky N, Kastner M, McKibbon KA, Straus S. Strategies for rehabilitation professionals to move evidence-based knowledge into practice: a systematic review. J Rehabil Med. 2009; 41: 1024-1032.

52. Glegg SM, Holsti L, Stanton S, Hanna S, Velikonja D, Ansley B, Sartor D, Brum C. Evaluating change in virtual reality adoption for brain injury rehabilitation following knowledge translation. Disabil Rehab: Assist Tech. 2017; 12: 217-226.

53. Levac D, Glegg SM, Camden C, Rivard LM, Missiuna C. Best practice recommendations for the development, implementation, and evaluation of online knowledge translation resources in rehabilitation. Phys Ther. 2015; 95: 648-662.

54. Bernhardsson S, Lynch E, Dizon JM, Fernandes J, Gonzalez-Suarez C, Lizarondo L, Luker J, Wiles L, Grimmer K. Advancing evidence-based practice in physical therapy settings: multinational perspectives on implementation strategies and interventions. Phys Ther. 2016; 97: 51-60.

55. Clinton-McHarg T, Young SL, Tzelepis F, Regan T, Fielding A, Skelton E et al. Psychometric properties of implementation measures for public health and community settings and mapping of constructs against the Consolidated Framework for Implementation Research: a systematic review. Implement Sci. 2016; 11:148. DOI 10.1186/s13012-016-0512-5 
56. Leeman J, Birkin SA, Powell BJ, Rohweder C, Shea C. Beyond "implementation strategies": classifying the full range of strategies used in implementation science and practice. Implement Sci. 2017; 12:125. DOI 10.1186/s13012-017-0657-x

57. Peters DH. Implementation research: what it is and how to do it. BMJ. 2013:347:f6753.

58. Fisher RJ, Cobley CS, Potgeiter I, Moody A, Nouri F, Gaynor C et al. Is stroke early supported discharge still effective in practice? A prospective comparative study. Clin Rehab. 2016; 30: 268-276.

59. Kindon S, R. Pain, Kesby M (Eds). Participatory action research: approaches and methods. 2007; Routledge, London.

60. Pawson R, Tilley N. Realistic evaluation. 1997: Sage Publications, London.

61. Proctor E, Silmere H, Raghaven R, Hovmand P, Aarons G, Bunger A et al. Outcomes for implementation research: conceptual distinctions, measurement challenges, and research agenda. Administration and Policy in Mental Health and Mental Health Services Research. 2011; 38: 65-76.

62. Haji F, Morin MP, and Parker K. Rethinking programme evaluation in health professions education: beyond 'did it work?'. Med Ed. 2013; 47: 342-351.

63. Bar-Yam, Y., Complexity rising: From human beings to human civilization, a complexity profile. 2002; NESCO Encyclopedia of Life Support Systems, Cambridge MA.

64. Deming, W. E. 1993. The New Economics For Industry, Government \& Education. Cambridge: Massachusetts Institute of Technology Center for Advanced Engineering Study

65. Sanders J, Fitzpatrick JM. Improving service user self-management: development and implementation of a strategy for the Richmond Response and Rehabilitation Team. BMJ Open Qual. 2017; 6: e000126. 
66. Chambers DA, Glasgow, Stange KC. The dynamic sustainability framework: addressing the paradox of sustainment amid ongoing change. Implement Sci. 2013; 8: 117. doi.org/10.1186/1748-5908-8-117

67. Langhorne P, Widen-Holmqvist L. Early supported discharge trialists. Early supported discharge after stroke. J Rehabil Med. 2007; 39: 269-269.

68. Graham ID, Logan J, Harrison MB, Straus SE, Tetroe J, Caswell W, Robinson N. Lost in knowledge translation: time for a map? Journal of continuing education in the health professions. 2006; 26: 13-24.

69. Fisher RJ, Gaynor C, Kerr M, Langhorne P, Anderson C, Bautz-Holter E et al. A consensus on stroke: early supported discharge. Stroke. 2011: 42: 1392-1397.

70. Cobley CS, Fisher RJ, Chouliara N, Kerr M, Walker M. A qualitative study exploring patients' and carers' experiences of Early Supported Discharge services after stroke. Clin Rehab. 2013; 27: $750-757$.

71. Connell LA, McMahon NE, Harris JE, Watkins CL, Eng JJ. A formative evaluation of the implementation of an upper limb stroke rehabilitation intervention in clinical practice: a qualitative interview study. Implement Sci. 2014:9:1:90. doi: 10.1186/s13012-014-0090-3.

72. Connell LA, McMahon NE, Tyson SF, Watkins CL, Eng JJ. Case Series of a Knowledge Translation Intervention to Increase Upper Limb Exercise in Stroke Rehabilitation. Phys. Ther. 2016; 96: 930-1937.

73. Connell LA, McMahon NE, Tyson SF, Watkins CL, Eng JJ. Development of a behaviour change intervention to increase upper limb exercise in stroke rehabilitation. Implement Sci. 2015; 10: 34. doi.org/10.1186/s13012-015-0223-3 
74. Connell LA, McMahon NE, Tyson SF, Watkins CL, Eng JJ. Mechanisms of action of an implementation intervention in stroke rehabilitation: a qualitative interview study. BMC Health Serv Res. 2016; 1: 534.

75. Bernhardsson S, Larsson ME. Does a tailored guideline implementation strategy have an impact on clinical physiotherapy practice? A nonrandomized controlled study. J Eval Clin Pract. 2018; e-publication ahead of print: doi: 10.1111/jep.12958

76. Sezier A, Mudge S, Kayes S, Kersten P, Payne D, Harwood M, et al. Development of a toolkit to enhance care processes for people with a long-term neurological condition: a qualitative descriptive study. BMJ Open. 2018; 8: e022038. Doi: 10.1136/bmjopen-2018-022038.

77. Harvey, G. and A. Kitson, PARIHS revisited: from heuristic to integrated framework for the successful implementation of knowledge into practice. Implement Sci. 2015:11:1:33.

78. Michie S, Van Stralen MM, West R. The behaviour change wheel: a new method for characterising and designing behaviour change interventions. Implement Sci. 2011; 6: 42. https://doi.org/10.1186/1748-5908-6-42

79. Barwick M. Checklist to Assess Organizational Readiness (CARI) for EIP Implementation. 2011; Hospital for Sick Children, Toronto.

80. Rapley T, Girling M, Mair F, Murray E, Treweek S, McColl E et al. Improving the normalization of complex interventions: part 1 - development of the NoMAD instrument for assessing implementation work based on normalization process theory (NPT). BMC Medical Research Methodology. 2018; 18: 133. doi.org/10.1186/s12874-018-0590-y

81. Huijg JM, Gebhardt WA, Dusseldorp E, Verheijdeb MW, van der Zouwe, Middelkoop BJC et al. Measuring determinants of implementation behavior: psychometric properties of a questionnaire based on the theoretical domains framework. Implement Sci. 2014; 9: 33. doi.org/10.1186/1748-5908-9-33. 
82. Alcalde-Rabanal JE, Becerril-Montekio VM, and Langlois EV. Evaluation of Communities of Practice performance developing implementation research to enhance maternal health decision-making in Mexico and Nicaragua. Implement Sci. 2018; 13: 41. doi.org/10.1186/s13012-018-0735-8.

83. Kinsella E and Caty M. Reflective practice for allied health: theory and applications in English LM (Ed), Adult education and health. 2012; University of Toronto Press, London.

84. Jones F and Bailey N, How can we train stroke practitioners about patient self-management? Description and evaluation of a pathway wide training programme. European Journal for Person Centered Healthcare. 2013; 1: 246-254.

85. Ward VL, House A, Hamer S. Knowledge brokering: the missing link in the evidence to action chain? Evidence \& policy: a journal of research, debate and practice. 2009; 5: 267-279.

86. Ward VL, House A, and Hamer S. Knowledge brokering: exploring the process of transferring knowledge into action. BMC Health Serv Res. 2009; 9: 12. doi.org/10.1186/1472-6963-9-1 
Table 1. Case studies illustrating implementation approaches in rehabilitation

Case study 1: Evaluating the benefits of Early Supported Discharge after stroke in real world settings

Aims: Although national stroke guidelines in many countries recommend the provision of ESD, based on randomised controlled trial (RCT) evidence [67], it is unclear if the benefits seen in RCT conditions are still apparent when ESD is implemented in practice. This series of studies aimed to examine if Early Supported Discharge (ESD) is still beneficial when operating in the unpredictable and complex context of frontline healthcare provision.

Methods: A qualitative evaluation of effectiveness of two ESD services, that had adopted defined evidence based core components, and had made context-dependent modifications. Damschroder's Consolidated Framework for Implementation Research (CFIR) and Graham's Knowledge to Action model offered theoretical frameworks with which to guide the research [21] [68]. First, the aim was to identify essential characteristics ('core components') that theory suggests need to be implemented for ESD to be effective in practice (knowledge creation phase) [69]. Then the aim was to investigate the context in which ESD services were operating. This enabled investigation of the 'adaptable periphery' - adaptable elements, structures or systems that may need to be modified for the intervention to be embedded successfully in practice [34] [70]. Improvement activities were designed and delivered to support and sustain evidence based ESD delivery, using prospective comparative study methods.

Findings: Studies demonstrated that ESD services reduced length of hospital stay and accelerated stroke patient recovery, showing that benefits were achievable in a real world setting [58].

Case study 2: improving upper limb exercise provided to people with stroke in inpatient rehabilitation

Aims: To develop and implement a clinically feasible upper limb exercise programme after stroke This study evaluated how RCT-informed upper limb intervention was used in real world clinical practice [71] [28] using implementation theories.

Methods: Interviews with therapists already using the intervention in practice:

- Interview guide (how therapists found out about intervention, processes used to implement intervention, how therapists used intervention) informed by Normalisation Process Theory (NPT)

- CFIR used to guide data analysis of factors influencing implementation and use of intervention

- Survey design (exploring therapists' opinions of using intervention) informed by CFIR to elicit information about intervention characteristics and characteristics of therapists

Findings: The studies identified factors that influenced implementation, and also highlighted challenges with fidelity when the intervention was used in the real world. We then developed and evaluated a behaviour change intervention to increase upper limb exercise in 3 stroke rehabilitation units:

- Behaviour change wheel guided selection of behaviour change strategies [72, 73]

- Theoretical Domains Framework guided analysis of mechanisms of action to explain how behaviour change intervention produced change [74]

This case series is an example of how a rigorous research-informed knowledge translation process resulted in practice change. 
Methods: The strategy was based on the Grol and Wensing implementation of change model [46], which is a synthesis of many different behaviour change theories that are relevant for implementation research. The theories on which the model is based relate to individual professionals, as well as to the influence of social interaction and organisational and economic context. The model, comprising five steps, was adapted to the clinical and organisational context of primary care physiotherapy in the region of Västra Götaland in Sweden. As part of this model, determinants of guideline use were investigated in a baseline survey [11], and the implementation strategy was tailored to address these determinants. The strategy comprised several components, the core component being an educational seminar in which the guidelines were presented and discussed. This seminar was conducted in physiotherapy clinics across half the region of Västra Götaland, while the other half served as control group. Effects of guideline implementation were evaluated in a post-implementation survey, which showed that the tailored, multicomponent guideline implementation significantly increased awareness of, knowledge of, and access to guidelines [14].

Findings: Use of guidelines was significantly affected among those who attended the implementation seminar. However, the impact of the guideline implementation on clinical practice was very limited, due to practice being in line with evidence already before the guidelines were implemented [75].

Case study 4: Implementation of a Living Well Toolkit into diverse rehabilitation settings Aims: We aimed to develop, and put into practice, a Living Well Toolkit to support key processes for people with long-term neurological conditions (person-centred communication, building selfmanagement skills, and coordination of long-term care).

Methods: We employed a participatory informed design approach, premised on the notion that understanding and valuing healthcare users' experiences in addition to engaging key stakeholders in the development of the toolkit would be fundamental to its success [48]. We explored perspectives of people with a long-term neurological condition, family, clinicians and other key stakeholders on three key processes. We developed themes from this data, which we used to develop the content of the toolkit [76]. The toolkit was then introduced in four rehabilitation settings. Individual and focus group interviews were carried out with patients $(n=11)$ and clinicians $(n=14)$. Data were analysed using NPT as a framework to inform revisions to the toolkit and future implementation processes.

Findings: There was widespread support for the principles underpinning the toolkit. However, it was less clear how it was envisaged the toolkit could support those practices (NPT: coherence) impacting buy-in from clinicians (NPT: cognitive participation). The built-in flexibility regarding who, how and to what extent the toolkit can be used made it difficult to operationalise in practice (NPT: collective action). Use of the Toolkit appeared more likely when it was perceived to augment existing processes (e.g. goal setting) rather than detract from 'doing' therapy (NPT: collective action, reflexive monitoring). 
Table 2. Examples of tools related to implementation processes

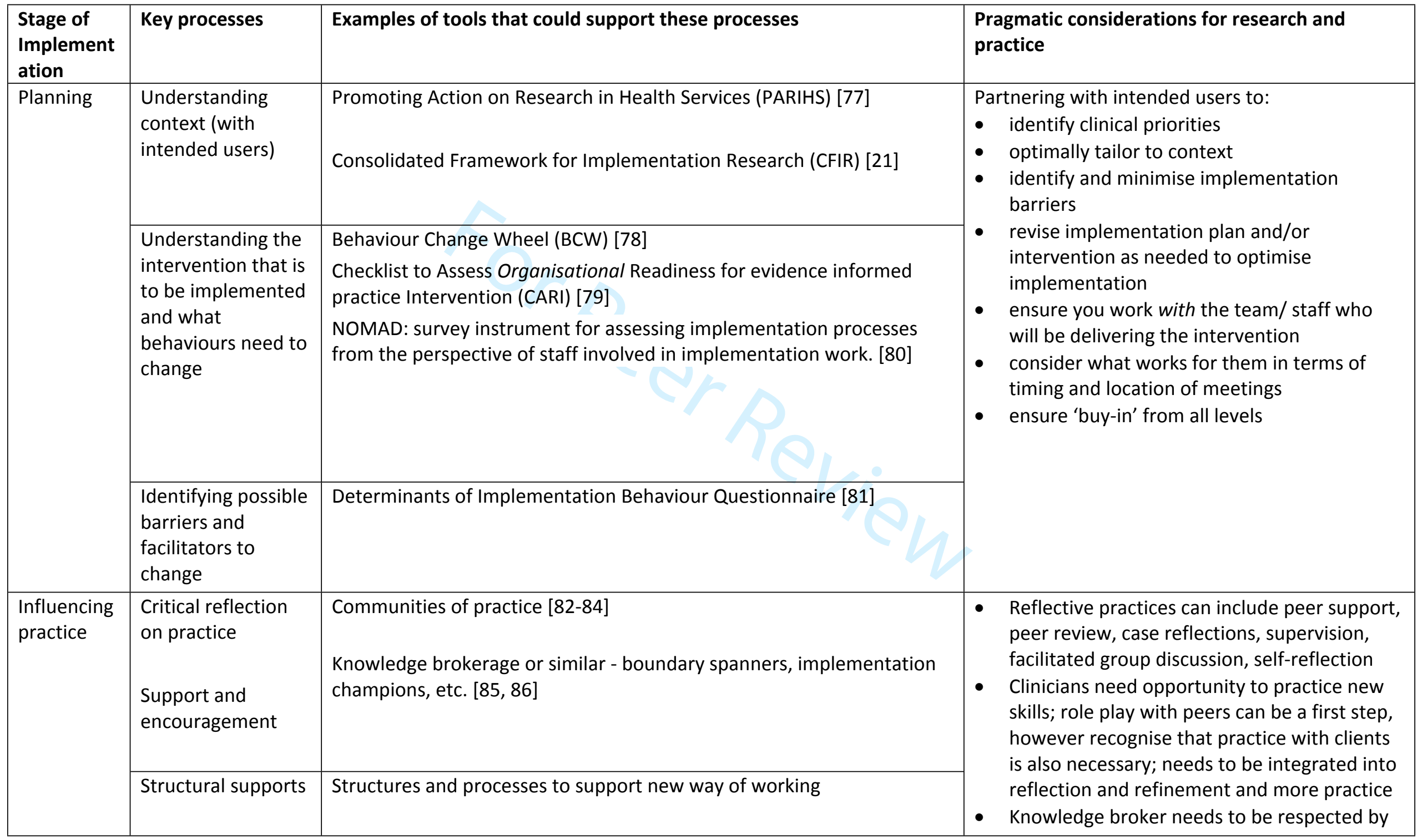




\begin{tabular}{|c|c|c|c|}
\hline & $\begin{array}{l}\text { Tailoring the } \\
\text { intervention to } \\
\text { context }\end{array}$ & $\begin{array}{l}\text { Behaviour Change Techniques (selection of most appropriate tools will } \\
\text { be context dependent, hence the planning phase being so important) }\end{array}$ & $\begin{array}{l}\text { - } \text { clinicians } \\
\text { - clinicians perceive an immediate benefit (to } \\
\text { then more likely to implement } \\
\text { - If clinicians perceive intervention fits with } \\
\text { practice, then more likely to implement } \\
\text { - Clinicians more likely to make change if } \\
\text { perceive work environment (including } \\
\text { colleagues) supportive of change }\end{array}$ \\
\hline $\begin{array}{l}\text { Monitoring } \\
\text { and review }\end{array}$ & 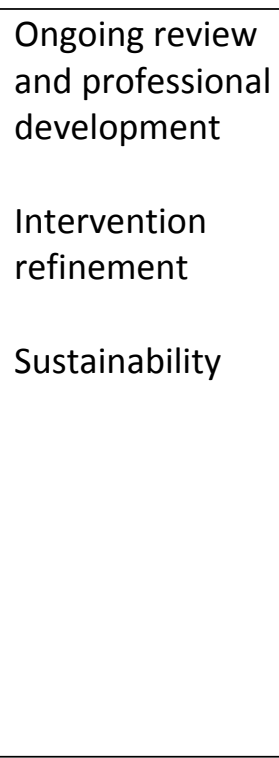 & $\begin{array}{l}\text { Recognise that implementation is a dynamic and ongoing process. } \\
\text { Review needs to happen at: } \\
\text { a) an individual level: individual clinicians reflecting in an ongoing way } \\
\text { over knowledge use, challenges and tensions, and recognising need } \\
\text { for ongoing professional development } \\
\text { b) at broader implementation strategy level: ongoing evaluation and } \\
\text { monitoring of knowledge use and behaviour change to determine if } \\
\text { implementation intervention is being effective or whether } \\
\text { refinements need to be made to optimise uptake } \\
\text { NOMAD, linked to NPT, is an evaluative tool to focus on } \\
\text { implementation, findings can be used to modify implementation } \\
\text { process constructively. }\end{array}$ & 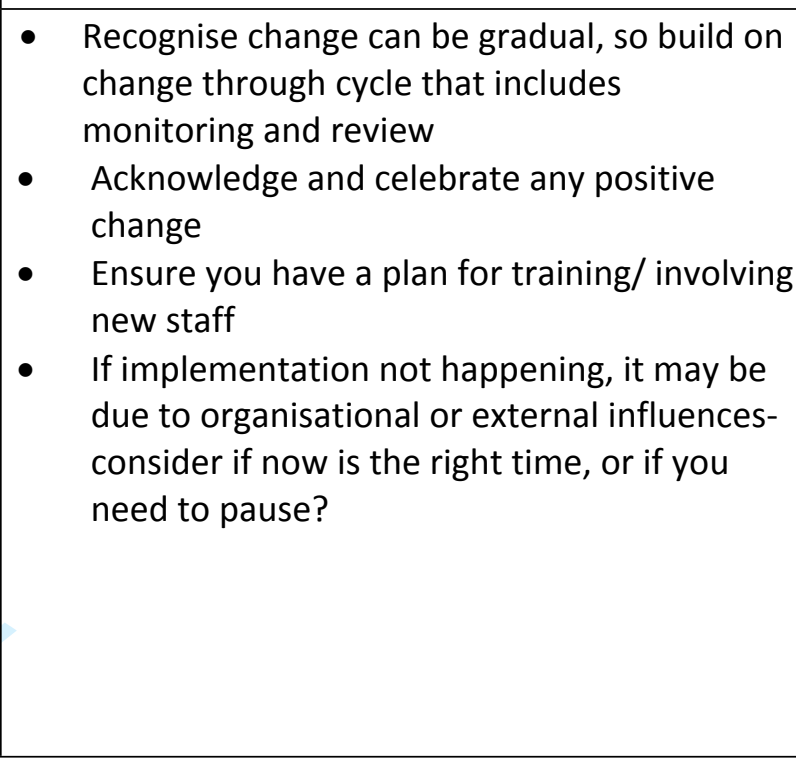 \\
\hline
\end{tabular}




\section{Figure 1. The Implementation Roadmap for Rehabilitation}

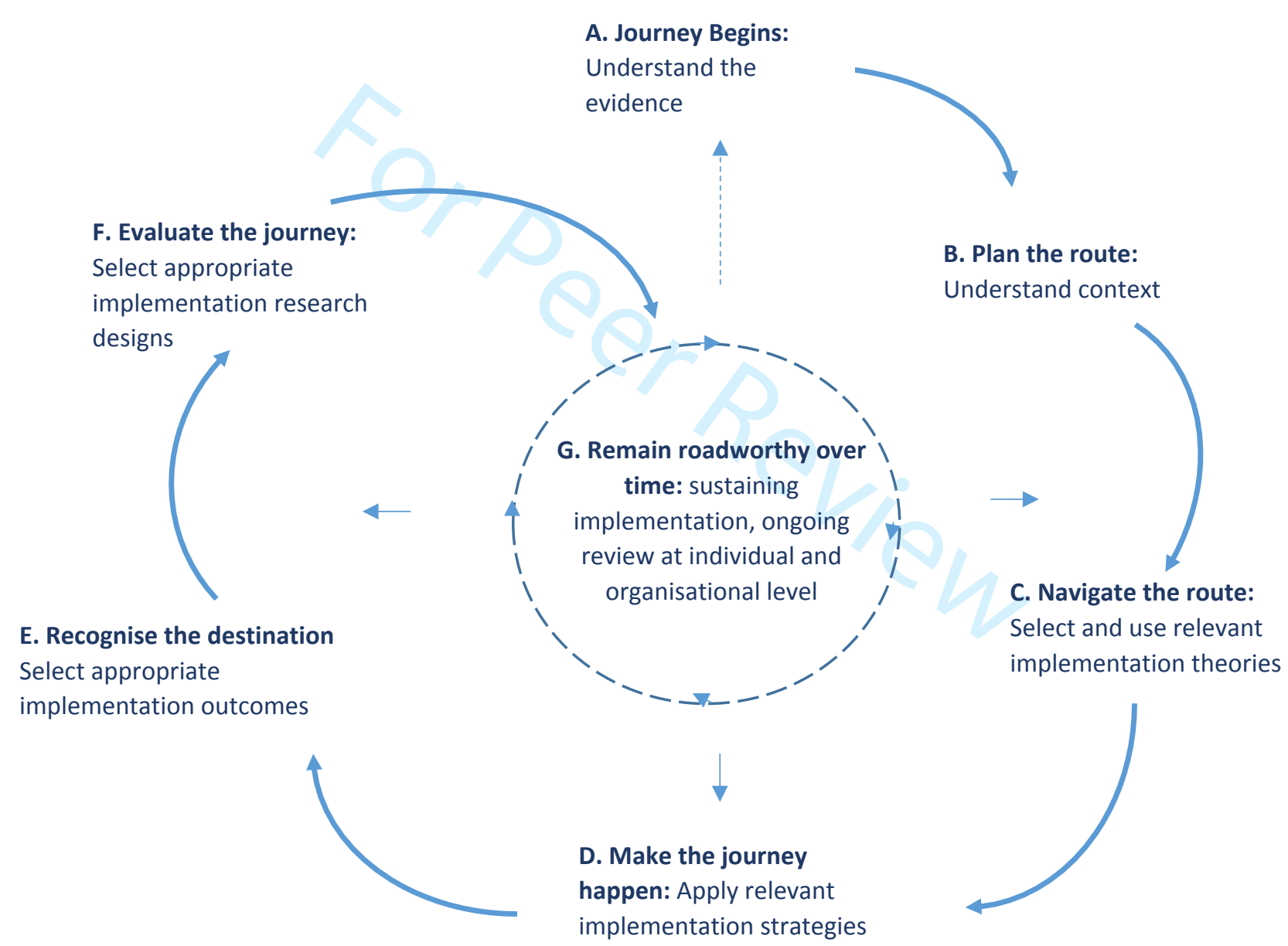

